\title{
Intracystic Carcinoma of the Breast: Report of Two Cases
}

\author{
Enver İlhan ${ }^{1}$, Orhan Üreyen ${ }^{1}$, Abdullah Şenlikci ${ }^{1}$, Ayşe Yağci ${ }^{2}$, Eyüp Yeldan ${ }^{1}$, Tarık Salman³ ${ }^{3}$ Mehmet Tahsin Tekeli ${ }^{1}$ \\ ${ }^{1}$ Clinic of General Surgery, İzmir Training and Research Hospital, İzmir, Turkey \\ ${ }^{2}$ Clinic of Pathology, İzmir Bozyaka Training and Research Hospital, İzmir, Turkey \\ ${ }^{3}$ Medical Oncology Service, İzmir Bozyaka Training and Research Hospital, İzmir, Turkey
}

\begin{abstract}
Intracystic papillary carcinoma of the breast (IPC) is usually seen in postmenopausal elderly women. Its prognosis is much better than other type of breast tumors, and usually do not contain invasive components. Surgical excision with negative margins and axillary sentinel lymph node sampling is the recommended treatment. Two cases of intracystic papillary carcinoma of the breast that was treated at our clinic are herein presented. Both cases were postmenopausal, were both positive for estrogen and progesterone receptors and negative for HER 2. They underwent breast-conserving surgery. One patient had an invasive focus, therefore axillary lymph node sampling was performed, and the sentinel lymph node was not metastatic. This patient received hormonal therapy as well as radiotherapy. In the other case, there was no invasive focus and the surgical margins were negative, therefore, additional surgery was not performed. The patient is receiving hormonal therapy. Intracystic carcinoma of the breast should be kept in mind especially in elderly patients with breast cysts, with clinically or radiologically suspicious features, and biopsy and local excision should be considered. Although there is not any standard approach for patients with IPC, each patient must be evaluated for surgery and should be individually assessed in terms of adjuvant therapy
\end{abstract}

Key words: Cystic breast cancer, intra-cystic papillary carcinoma, breast cancer

\section{Introduction}

Intracystic papillary carcinoma (IPC) is an extremely rare tumor that constitutes $0.5-2 \%$ of all breast cancers (1). Although rare, this type of breast cancer is known to have very good prognosis (2). Its diagnosis is very difficult as compared to other types of breast carcinomas, since the criteria for diagnosis and treatment have not been yet defined (3). They usually present as a large cystic mass. The tumor is often retroareolar, and is well-circumscribed. In some cases, nipple discharge may be the first sign (4). On ultrasonography (US) it may appear cystic, semi solid or solid (5). Microcalcifications may accompany the lesion on mammograms (4). There are no specific clinical or radiologic signs. Magnetic resonance imaging (MRI) may be useful in differentiating benign tumors from invasive tumors (3). The diagnosis of this tumor can be made by either fine needle aspiration biopsy or core-biopsy. Excisional biopsy is required if these methods are inconclusive (3). Surgical excision of the cyst is recommended in the presence of atypia on biopsy, a high-risk lesion, the presence of malignancy or radiologic-histologic discordance. If the US or mammography are suspicious for IPC then excisional biopsy should be performed as the first approach (5).

IPC is characterized by papillary growth within macrocysts. They usually do not exhibit invasive growth over the cyst wall, so they are often treated as ductal carcinoma in situ (DCIS). Although treatment methods are still controversial, surgery remains the treatment of choice (3). Endocrine therapy and radiation therapy are used in most medical centers but the evidence indicating that this method improves prognosis is still insufficient (5). Two patients with IPC who were treated at our clinic are presented together with the relevant literature.

\section{Case Presentation}

\section{Case 1}

A 56-year-old postmenopausal women underwent cyst excision from her right breast at another center, and was diagnosed with "intracystic papillary carcinoma of the breast" upon pathologic evaluation. The surgical margins were negative, and she was referred to our clinic. The existing pathology blocks were re-evaluated at our hospital's pathology department and were interpreted as "intracystic papil-

This study was presented as a poster at the $12^{\text {th }}$ National Breast Diseases Congress, 24-27 October 2013, Antalya, Turkey

Address for Correspondence:

Orhan Üreyen, Clinic of General Surgery, İzmir Training and Research Hospital, İzmir, Turkey

Received: 20.12.2013

Phone: +90 5056487748 e-mail: drureyen@yahoo.com 

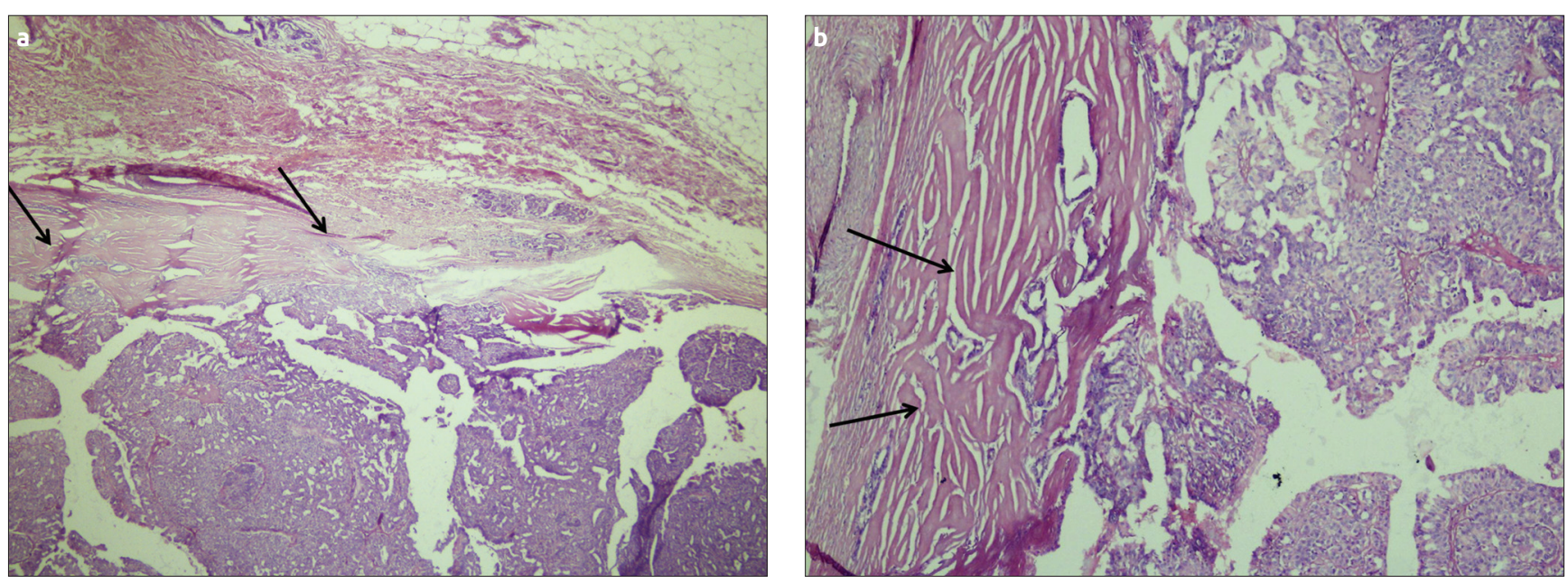

Figure 1. a, b. a) Invasive tumor area, extending beyond the capsule within the tumor that shows intracystic papillary growth. HEx40 b) Invasive tumor area, extending beyond the capsule within the tumor that shows intracystic papillary growth. HEx40

lary carcinoma of the breast with microinvasion" (Figure 1a, b). The estrogen receptor (ER) and progesterone receptors (PR) were positive. On US and MRI, secondary changes due to the previous operation on the right breast, and reactive lymphadenopathy on the right axilla were detected. The previous mammography was classified as BIRADS 0 . Sentinel lymph node sampling was performed and no metastasis was detected. There were no pathologic findings on systemic screening. The patient is receiving hormonotherapy after radiotherapy.

\section{Case 2}

A 50-year-old postmenopausal woman was admitted due to a palpable mass in her right breast. Her US showed a $3.5-\mathrm{cm}$ hypoechoic mass containing hypoechoic debris and hyperechoic septa at 11 o'clock position in the right breast. On MRI and mammography, a $3.5 \mathrm{~cm}$ mass was observed in the same region that was suspicious for complicated hemorrhagic cyst, hemorrhagic solid lesion or sarcoma phyllodes. The patient underwent excisional biopsy, and the histopathology evaluation revealed "intracystic papillary carcinoma of the breast that did not contain an invasive focus" (Figure 2). The surgical margins were negative, and ER and PR were positive. Screening for distant metastases did not show any additional pathology. Since there was no invasive focus within the tumor, a sentinel lymph node sampling was not applied. The patient is still receiving hormonotherapy.

\section{Discussion and Conclusions}

IPC is a rare entity constituting approximately 1 to $2 \%$ of all breast cancers (6). It may rarely be seen in men, accounting for nearly 5 to $7.5 \%$ of all male breast carcinomas (7). Until recently, the distinction between these types of cancer was not clear and IPC was thought to have a poor prognosis. Currently, it is known that they have a better prognosis than DCIS (4). Patients usually present with a palpable mass in the breast, bloody nipple discharge, or radiographic abnormalities. Both of our cases presented with a breast mass.

The tumor histologically contains a nodule with papillary carcinoma, which is surrounded by a dilated tubule coated with fibrovascular stroma within a thick fibrous capsule (8). Although it may be seen in any age, it is usually detected in post-menopausal women and at a higher age than the mean age for breast cancer. The mean age is reported as 65 years in the literature $(3,8)$. Although both of our cases were post-

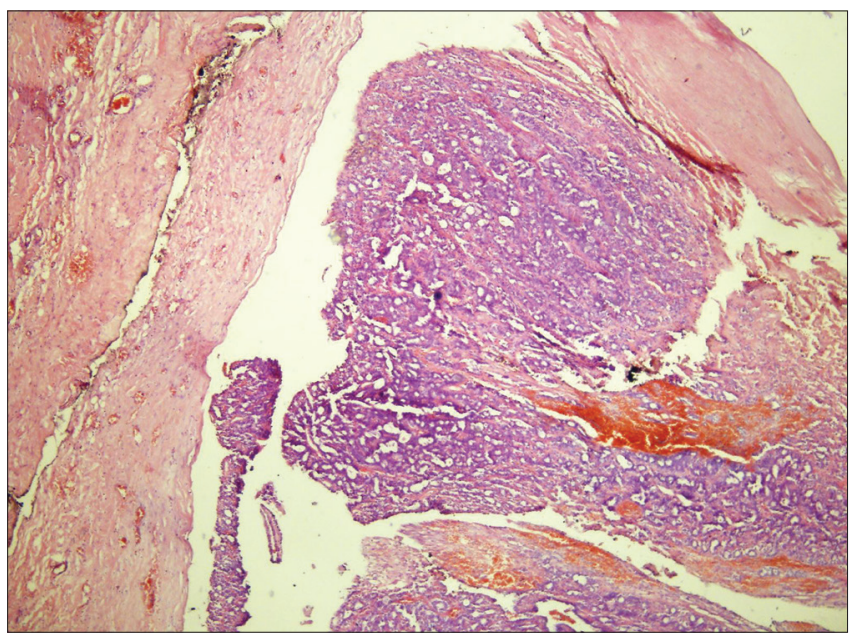

Figure 2. The tumor that shows intracystic papillary growth without invasion. HEx40

The classification of IPC varies in the literature (9). Generally, it is accepted as a non-invasive breast cancer and as a low-grade DCIS subtype, however, there are classifications where it is regarded as invasive breast carcinoma (2). The presence of myoepithelial cells around papillary carcinoma is considered as a sign of invasive focus rather than in situ tumor (8). However, recent studies where myoepithelial cells were not detected around papillary carcinoma with DCIS created doubts on the presence of another type of IPC between in situ and invasive forms $(8,9)$. The rate of invasive focus is reported as $40 \%$ in many series, although it may vary $(2,8,10)$. The rate of lymph node metastases range between $0-36 \%$, and is much lower than that in normal breast cancer (3). Some studies reported simultaneous liver metastasis at the time of diagnosis of invasive IPC $(3,11)$. Although it is known to have a very good prognosis, this paradoxical situation should not be ignored both in diagnosis and in treatment (6). One of our cases had an invasive focus. Distant metastasis was not detected in both cases.

Fine-needle aspiration biopsy and core biopsy are often performed for its diagnosis. However, cytological false negative rate is quite high (12). Tomonori et al. (3) stated that its preoperative diagnosis was very difficult, and suggested excisional biopsy for the diagnosis of these lesions, since it cannot be diagnosed with either fine-needle or core-biopsy. 
There is no agreement on its treatment, because it is a rare type of breast cancer with only case reports or series in the literature. In general, the treatment includes breast conserving surgery with wide local excision or mastectomy, followed by sentinel lymph node biopsy in its invasive forms and axillary lymph node dissection according to the pathological result, followed by adjuvant therapy. In terms of adjuvant therapy, if ER/PR is positive and HER 2 is negative, the choice of treatment is tamoxifen $(1,6,13)$. Although the focus is on tamoxifen as choice of endocrine therapy, there is no conclusive evidence for the indication of endocrine treatment (9). Both of our patients were ER/PR strong positive and HER 2 negative, consistent with literature. Due to the invasive focus on one of the cases, breast-conserving surgery was followed by radiotherapy and hormonotherapy, while breastconserving surgery followed by hormonotherapy was used in the other patient who did not have an invasive component.

Grabowski et al. (8) published the largest series in the literature with 917 patients, and stated that classification of IPC as in situ or invasive did not have a clinical significance, with excellent prognoses in both types. In addition, they advocated the treatment of all IPCs as DCIS. However, Solorzano et al. (1) emphasized that radiotherapy affected neither recurrence nor survival. On the other hand, Fayanju et al. (13) reported that adjuvant radiotherapy and hormonotherapy would reduce the risk of local recurrence in patients with DCIS under the age of 50 or those with microinvasion. Many studies have shown that tumor recurrence or mortality rate due to cancer was not increased in patients with breast conserving surgery $(1,8)$.

Lefkowitz et al. (2) emphasized that the growth pattern of IPC is quite slow. In addition, they reported the mean 10-year survival and disease-free survival rates as $100 \%$ and $91 \%$, respectively. Obviously, the prognosis of this disease is very good and there is not any adjuvant treatment regimen shown to improve disease-free survival. That is why, concerns on the potential risks of adjuvant therapy is emphasized (1). Despite all general treatment recommendations and principles, the treatment of IPC remains to be controversial (6).

In conclusion, IPC of the breast should be kept in mind especially in post menopausal patients with clinically or radiologically suspicious breast cysts, and biopsy and local excision should be considered. Although there is not any standard approach for patients with this diagnosis, each patient must be evaluated for surgery and should be individually assessed in terms of adjuvant therapy.

Peer-review: Externally peer-reviewed.

Author Contributions: Concept - E.İ., A.Y., O.Ü.; Design - M.T.T., E.Y.; Supervision - M.T.T., E.İ.; Funding - O.Ü., A.Ş., T.S.; Materials
- E.İ., T.S.; Data Collection and/or Processing - O.Ü., E.Y.; Analysis and/or Interpretation - E.İ., M.T.T.; Literature Review - A.Ş., A.Y.; Writer - A.Y., E.İ., A.Ş.; Critical Review - E.Y., T.S., O.Ü.

Conflict of Interest: No conflict of interest was declared by the authors.

Financial Disclosure: The authors declared that this study has received no financial support.

\section{References}

1. Solorzano CC, Middleton LP, Hunt KK, Mirza N, Meric F, Kuerer HM, Ross MI, Ames FC, Feig BW, Pollock RE, Singletary SE, Babiera G. Treatment and outcome of patients with intracystic papillary carcinoma of the breast. Am J Surg 2002; 184:364-368. (PMID:12383904) [CrossRef]

2. Lefkowitz M, Lefkowitz W, Wargotz ES. Intraductal (intracystic) papillary carcinoma of the breast and its variants: a clinicopathological study of 77 cases. Hum Pathol 1994; 25:802-809. (PMID:8056421) [CrossRef]

3. Akagi T, Kinoshita T, Shien T, Hojo T, Akashi-Tanaka S, Murata Y. Clinical and pathological features of intracystic papillary carcinoma of the breast. Surg Today 2009; 39:5-8. (PMID:19132460) [CrossRef]

4. Oran ES, Mecit N, Calay Z, İğdem Ş, Soybir G. Intracystic papillary carcinoma of the breast: A case report. The Journal of Breast Health 2010; 6:30-33.

5. Ait Benkaddour Y, El Hasnaoui S, Fichtali K, Fakhir B, Jalal H, Kouchani $\mathrm{M}$, Aboulfalah A, Abbassi H. Intracystic papillary carcinoma of the breast: report of three cases and literature review. Case Rep Obstet Gynecol 2012; 2012:979563. (PMID:22567530)

6. Reefy SA, Kameshki R, Sada DA, Elewah AA, Awadhi AA, Awadhi KA. Intracystic papillary breast cancer: a clinical update. Ecancermedicalscience 2013; 7:286. (PMID:23304242)

7. Shukla S, Singh S, Pujani M. Intracystic papillary carcinoma in a male breast following mastectomy for infiltrating ductal carcinoma. Indian J Cancer 2010; 47:349-351. (PMID:20587919) [CrossRef]

8. Grabowski J, Salzstein SL, Sadler GR, Blair S. Intracystic papillary carcinoma: a review of 917 cases. Cancer 2008; 113:916-920. (PMID: 18661510) [CrossRef]

9. Collins LC, Schnitt SJ. Papillary lesions of the breast: selected diagnostic and management issues. Histopathology 2008; 52:20-29. (PMID:18171414) [CrossRef]

10. Calderaro J, Espie M, Duclos J, Giachetti S, Wehrer D, Sandid W, Cahen-Doidy L, Albiter M, Janin A, de Roquancourt A. Breast intracystic papillary carcinoma: an update. Breast J 2009; 15:639-644. (PMID: 19735389) [CrossRef]

11. Okita R, Ohsumi S, Takashima S, Saeki T, Aogi K, Nishimura R. Synchronous liver metastases of intracystic papillary carcinoma with invasion of the breast. Breast Cancer 2005; 12:327-330. ( PMID: 16286915) [CrossRef]

12. Levine PH, Waisman J, Yang GC. Aspiration cytology of cystic carcinoma of the breast. Diagn Cytopathol 2003; 28:9-44. (PMID: 12508181) [CrossRef]

13. Fayanju OM, Ritter J, Gillanders WE, Eberlein TJ, Dietz JR, Aft R, Margenthaler JA. Therapeutic management of intracystic papillary carcinoma of the breast: The roles of radiation and endocrine therapy. Am J Surg 2007; 194:497-500. (PMID: 17826064) [CrossRef] 